\title{
Statistical Modelling of 3-Hourly Wind Patterns in Melbourne, Australia
}

\author{
Mayuening Eso*(**), Prashanth Gururaja* and Rhysa McNeil*(**)† \\ *Department of Mathematics and Computer Science, Faculty of Science and Technology, Prince of Songkla University, \\ Mueang Pattani, 94000, Thailand \\ **Centre of Excellence in Mathematics, Commission on Higher Education (CHE), Ministry of Education, Ratchathewi, \\ Bangkok, 10400, Thailand \\ $\dagger$ Corresponding author: Rhysa McNeil; rhysa.m@psu.ac.th
}

Nat. Env. \& Poll. Tech.

Website: www.neptjournal.com

Received: 31-05-2020

Revised: $25-07-2020$

Accepted: $31-07-2020$

Key Words:

Wind prevalence

Wind gust

Wind speed

Logistic and linear regression

\begin{abstract}
Modelling wind speed and trends helps in estimating the energy produced from wind farms. This study uses statistical models to analyze wind patterns in Melbourne, Australia. Three-hourly wind data during 2004-2008 was obtained from the Australian Government, Bureau of Meteorology, for Avalon Airport, Essendon Airport, Point Wilson, and View Bank stations. A logistic regression model was used to investigate the pattern of 3-hourly winds and gust prevalence while a linear regression model was applied to investigate wind speed trends. The 3-hour periods of the day, month, and year were used as the independent variables in the analysis. At four stations, wind speed and wind gust prevalence were mostly high between 9 AM and 6 PM. The monthly wind and wind gust prevalence were high from November to January while the highest annual prevalence occurred in 2007 . The wind speed increased from $7 \mathrm{AM}$ to $6 \mathrm{PM}$ within which the maximum occurred. The monthly wind speed increased from November to January where it attained the maximum, decreasing to a minimum in May. The annual mean wind speed was highest in 2007.
\end{abstract}

\section{INTRODUCTION}

Wind is the dominant air current that affects the Earth's climate. The movement of the wind on the Earth's surface has a diverse range of magnitude and is constantly changing direction. This intriguing wind behaviour has a tremendous impact on global climate and weather conditions (Csavina et al. 2014), ecosystems, and human life imbalance (Mitchell 2012). Sudden wind gusts have an enormous influence on climate and weather events (Cheng et al. 2014). Its extreme can cause an enormous amount of damage and destruction to man-made structures and result in devastation to humans and ecosystems (Jamaludin et al. 2016).

Several studies have investigated wind patterns over the Earth's surface. Studies of long-term austral summer wind speed trends over southern Africa have shown that a decline in wind speed was caused by deceleration of mid-latitude westerly winds, and Atlantic south-easterly winds with a poleward shift in the subtropical anticyclone (Nchaba et al. 2016). The average monthly maximum and minimum wind speeds in the United States from 1961 to 1990 reduced in spring and summer. The decreasing wind speeds in western and southeastern United States may be due to variable topography and high atmospheric pressures mostly throughout the year. However, the central and the northeastern regions have a gentle topography and are located near common storm tracks (Klink 1999). In Europe, high wind variability was evident over 140 years in the north-east Atlantic (Bett et al. 2013). In China, the warm and cold Arctic Oscillation and El Niño-Southern Oscillation phases have a significant influence on the probability distribution of wind speeds. Thus, internal climate variability is a major source of both interannual and long-term variability (Chen et al. 2013).

Daytime surface wind speeds were shown to be broadly consistent whereas night-time surface wind speeds are more positively skewed. However, in the mid-latitudes, these strongly positive skewness were shown to be associated with conditions of strong surface stability and weak lower-tropospheric wind shear (Mohanan et al. 2001).

The island continent of Australia features a wide range of climatic zones, from the tropical regions of the north, through to the arid expanses of the interior, to the temperate regions of the south. Australia experiences many of nature's more extreme weather phenomena, including tropical cyclones, severe storms, bushfires, and the occasional tornado. Australia's climate is largely determined by its latitudes, with the mainland lying between $10^{\circ}$ South to $39^{\circ}$ South, extending to $44^{\circ}$ South, and longitudes $112^{\circ}$ East and $154^{\circ}$ East (Trewin 2005). The average wind speed varies throughout the year with distinctive seasonal patterns. In the southern region, the strongest winds occur during 
winter (June-August) and spring (September-November). In terms of daily variation, wind speed increases in the afternoons (Coppin et al. 2003). The city of Melbourne lies on the latitude and longitude of $37.8136^{\circ} \mathrm{S}$ and $144.9631^{\circ} \mathrm{E}$, respectively. It is in the vulnerable zone of a significant increase in intense frontal systems which bring extreme winds and dangerous fire conditions (Hasson et al. 2009). An increase in the frequency of conditions makes the city conducive to thunderstorm development in the southern and eastern areas (Allen et al. 2014). The city is situated on the boundary of the very hot inland areas and the cool Southern Ocean and experiences frequent changes in weather conditions due to its geographical location. The autumn months (March-May) have lighter winds than other months (Bureau of Meteorology 1968). Prevailing winds come in over the poleward areas on the high-pressure area known as the subtropical ridge in the horse latitudes. These prevailing winds mainly blow from the west to the east and bring extra-tropical cyclones. The winds come predominantly from the southwest in the Northern Hemisphere and from the northwest in the Southern Hemisphere. These winds are stronger in the winter due to the lower atmospheric pressure over the poles. In this study, we aim to investigate the wind and wind gust prevalence using logistic regression models, and to analyze wind speed patterns in Melbourne using linear regression model.

\section{MATERIALS AND METHODS}

The 3-hourly wind observations of four selected stations, namely Essendon Airport, Avalon Airport, Point Wilson, and View Bank were obtained from the Australian Government, Bureau of Meteorology at (http://reg.bom.gov.au/reguser/) for the years 2004-2008. The measurements recorded for consecutive 3-hourly periods were associated with a wellknown primaeval Bronze-Age meteorological system, and ancient time metrics of the Roman system (Graham \& Kamm 2014); and noteworthy heuristic weather measurement instruments of Bureau of Meteorology, Australia (BOM 2011). Moreover, eight periods of 3 hours each during the day were classified into the following time intervals: mid-night, dawn, morning, forenoon, afternoon, evening, dusk, and night (Glickman \& Zenk 2000). The wind speed magnitude was measured in kilometres per hour $(\mathrm{km} / \mathrm{h})$ on the Earth's surface and the prevalence was classified as any occurrence of wind of at least $3 \mathrm{~km} / \mathrm{h}$ (Wheeler \& Wilkinson 2004) while wind speeds of at least $18 \mathrm{~km} / \mathrm{h}$ (Geer 1996) were classified as gusts as given in Table 1 .

\section{Statistical Methods}

The wind prevalence and wind gust prevalence are the binary outcomes, therefore logistic regression models were used to
Table 1: Wind observations prevalence and wind gust categories.

\begin{tabular}{|llllll|}
\hline stations & $\begin{array}{l}\text { Sample } \\
\text { size }\end{array}$ & \multicolumn{2}{l}{ Wind $(\mathrm{km} / \mathrm{h})$} & \multicolumn{3}{l|}{$\begin{array}{l}\text { Wind gust } \\
(\mathrm{km} / \mathrm{h})\end{array}$} \\
\cline { 3 - 6 } & & $<3$ & $\geq 3$ & $<18$ & $\geq 18$ \\
\hline Avalon Airport & 14,493 & 4,066 & 10,427 & 7,579 & 6,914 \\
Essendon Airport & 14,524 & 4,493 & 10,031 & 7,909 & 6,615 \\
Point Wilson & 14,293 & 2,495 & 11,798 & 5,205 & 9,088 \\
View Bank & 14,586 & 8,052 & 6,534 & 11,318 & 3,268 \\
\hline
\end{tabular}

investigate the wind pattern. The logistic regression model takes the following form:

$$
\ln \left(\frac{p_{i j k}}{1-p_{i j k}}\right)=\mu+\alpha_{i}+\beta_{j}+\gamma_{k},
$$

Where $p_{i j k}$ is the probability of wind or wind gusts occurring, $\mu$ is a constant, $\alpha_{i}$ is the coefficient for each period of the day, $\beta_{j}$ is the coefficient for each month of the year, and $\gamma_{k}$ is the coefficient for each year. The Receiver Operating Characteristic (ROC) curve (Westin 2001) was used as a measure of goodness-of-fit of the model. The ROC curve is popularly known for determining the capability of the prediction of a binary outcome.

The trends of wind speed of at least $3 \mathrm{~km} / \mathrm{h}$ was also investigated. Since the wind speed was a continuous outcome, a multiple linear regression model was used. The model takes the following form:

$$
y_{i j k}=\mu+\alpha_{i}+\beta_{j}+\gamma_{k}
$$

where $y_{i j k}$ represents wind speed at period $i$, month $j$ and year $k, \mu$ is the overall mean, $\alpha_{i}$ is the coefficient for each period of the day, $\beta_{j}$ is the coefficient for each month of the year, and $\gamma_{k}$ is the coefficient for each year. The goodness of fit of the model was assessed using the coefficient of determination (R-square) and Quantile-Quantile plots (Q-Q plots). Since the normality assumption was not satisfied, the wind speed values were transformed by taking the natural logarithm.

The sum contrasts (Tongkumchum \& McNeil 2009) were applied to obtain $95 \%$ confidence intervals (CI) to compare the fitted model means with the overall wind speed means. This contrast gives criteria to classify levels of the factor into three groups, according to whether each relating CI is greater than or equal to, or is less than the overall mean. All analysis was done in R (R Development Core Team 2008)

\section{RESULTS}

For each station, a logistic regression model (model 1) was fit to the 3-hourly wind prevalence from 2004 to 2008 with 3 categorical predictors. The first predictor was the 3-hourly period of the day with 8 factors, the second predictor was 
ROC Curves: Logistic Models
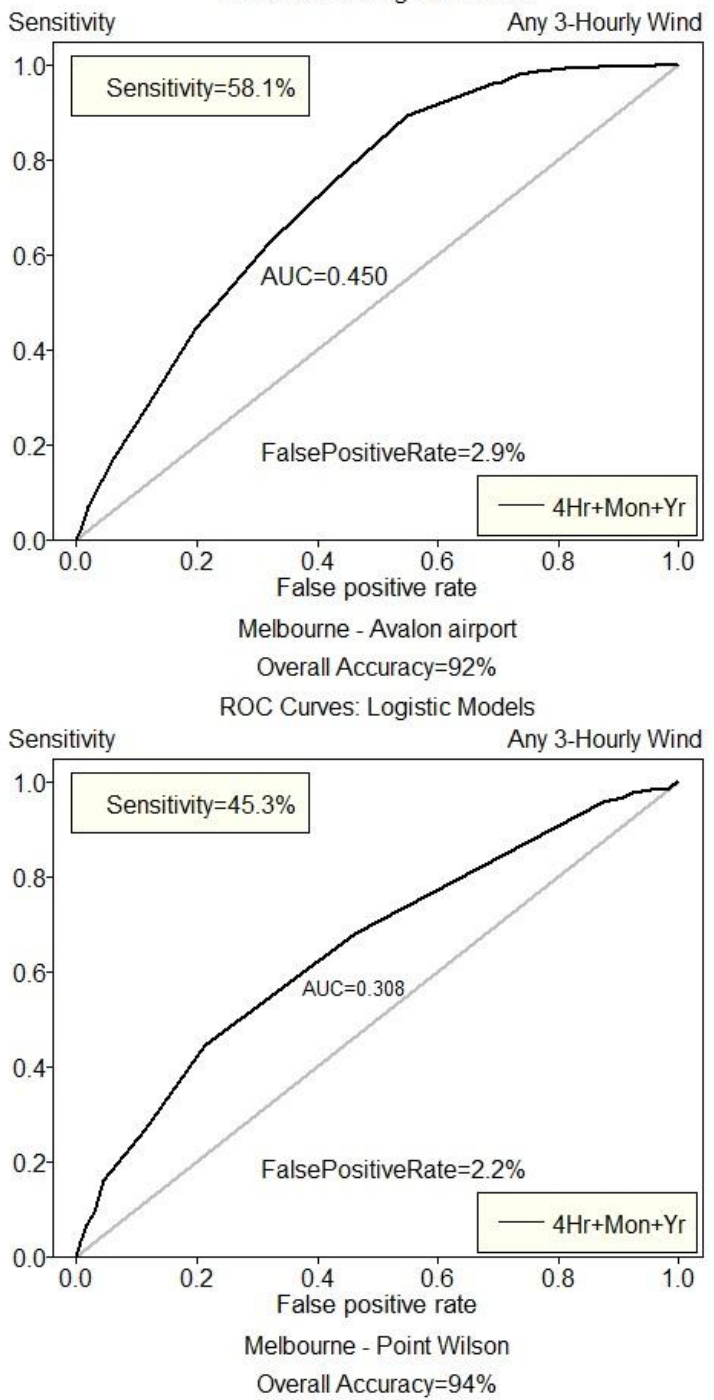

ROC Curves: Logistic Models

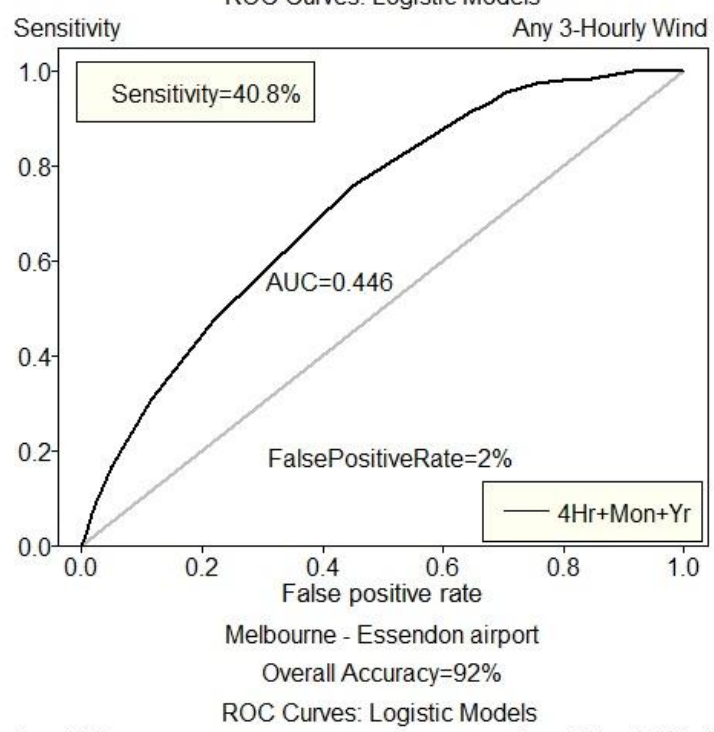

Any 3-Hourly Wind

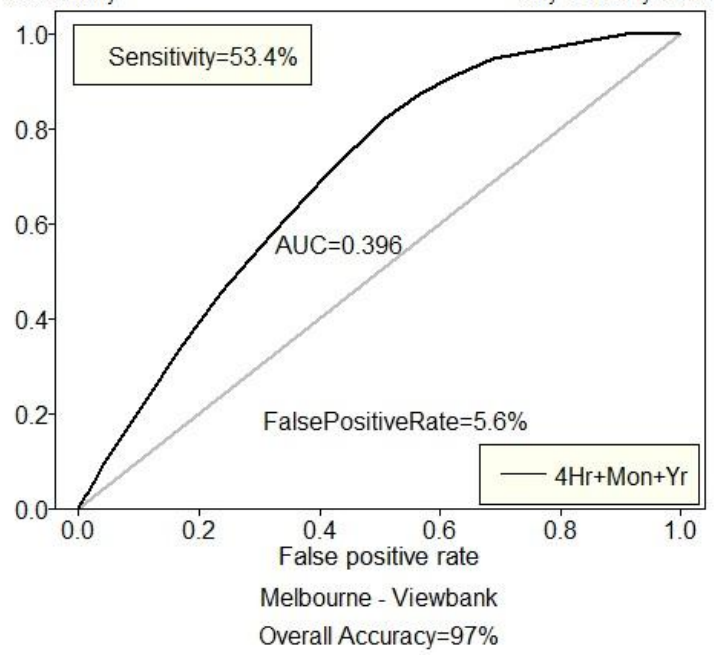

Fig. 1: ROC curves from the logistic regression models for the 3 hours of wind at 4 stations in Melbourne, Australia.

the month of the year (12 factors), and the third predictor was the year ( 5 factors). There were 26 parameters including the constant term in the model. The parameters were highly significant and influential in the model as displayed in Fig. 2 and Fig. 3. The ROC curve (Fig. 1) revealed area under the curve (AUC) values of $0.450,0.446,0.308$, and 0.396 for the four stations.

The overall accuracy at each station on correctly classifying the occurrence or non-occurrence of wind were $92 \%$, $92 \%, 94 \%$, and $97 \%$, the true positive rates were $58.1 \%$, $40.8 \%, 45.3 \%$, and $53.4 \%$, and the false positive rates were $2.9 \%, 2 \%, 2.2 \%$, and $5.6 \%$ respectively.

Fig. 2 and Fig. 3 show the patterns of wind prevalence for the day, month and year, and the crude percentage for the four stations. The horizontal red line denotes the overall percentage of wind prevalence at each station. The plot of the wind prevalence revealed that the patterns for the day and month were significantly different from the overall percentage for all stations.

At Avalon Airport and Essendon airport, there were quite similar patterns of wind prevalence with an overall average percentage of approximately $70 \%$. During the day, the highest wind prevalence occurred from 12 PM to 3 PM with around $90 \%$. The monthly wind prevalence was below the average from March to June. The yearly wind prevalence did not differ from the overall percentage.

At the Point Wilson station, the overall percentage of wind prevalence (over $80 \%$ ) was higher than the other three 
Wind Prevalence (\%) 14493 3-Hourly Records from Melbourne-Avalon-Airport: 2004-2008

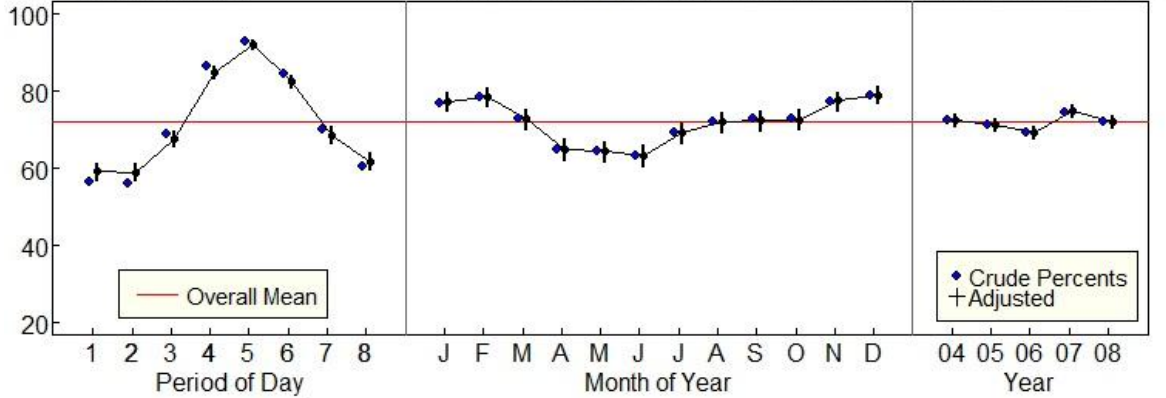

Wind Prevalence (\%) $\quad 14524$ 3-Hourly Records from Melbourne-Essendon-Airport 2004-2008

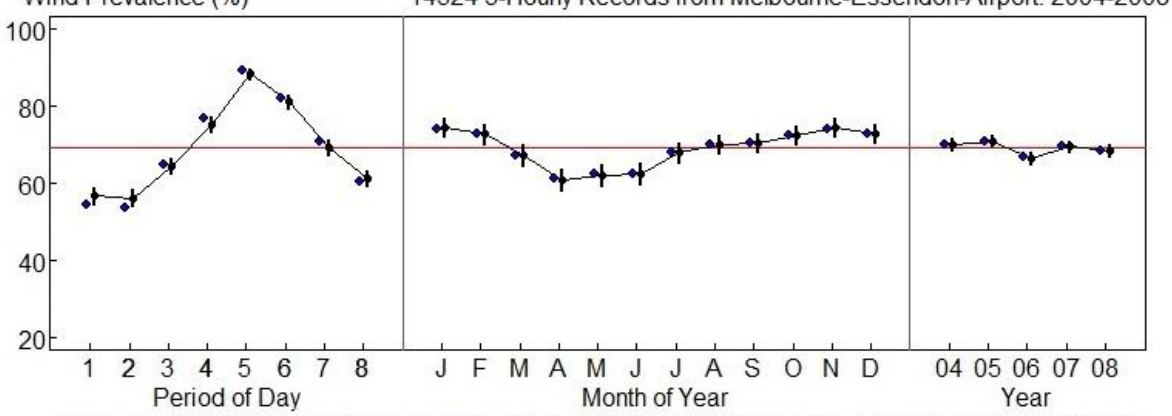

Note $-1=$ After $1 \mathrm{AM}$ and Before $3 \mathrm{AM}, 2=$ After $4 \mathrm{AM}$ and Before $6 \mathrm{AM}, 3=\mathrm{After} 7 \mathrm{AM}$ and Before $9 \mathrm{AM}$ $4=$ After $9 \mathrm{AM}$ and Before 12PM $5=$ After $12 \mathrm{PM}$ and Before 3PM $6=$ After $3 \mathrm{PM}$ and Before 6PM $7=$ After $6 \mathrm{PM}$ and Before 9PM, 8 = After 9PM and Before 12PM The hour denotes the starting hour of the 3 -hour time period

Fig. 2: Patterns of wind prevalence at Avalon Airport and Essendon Airport.
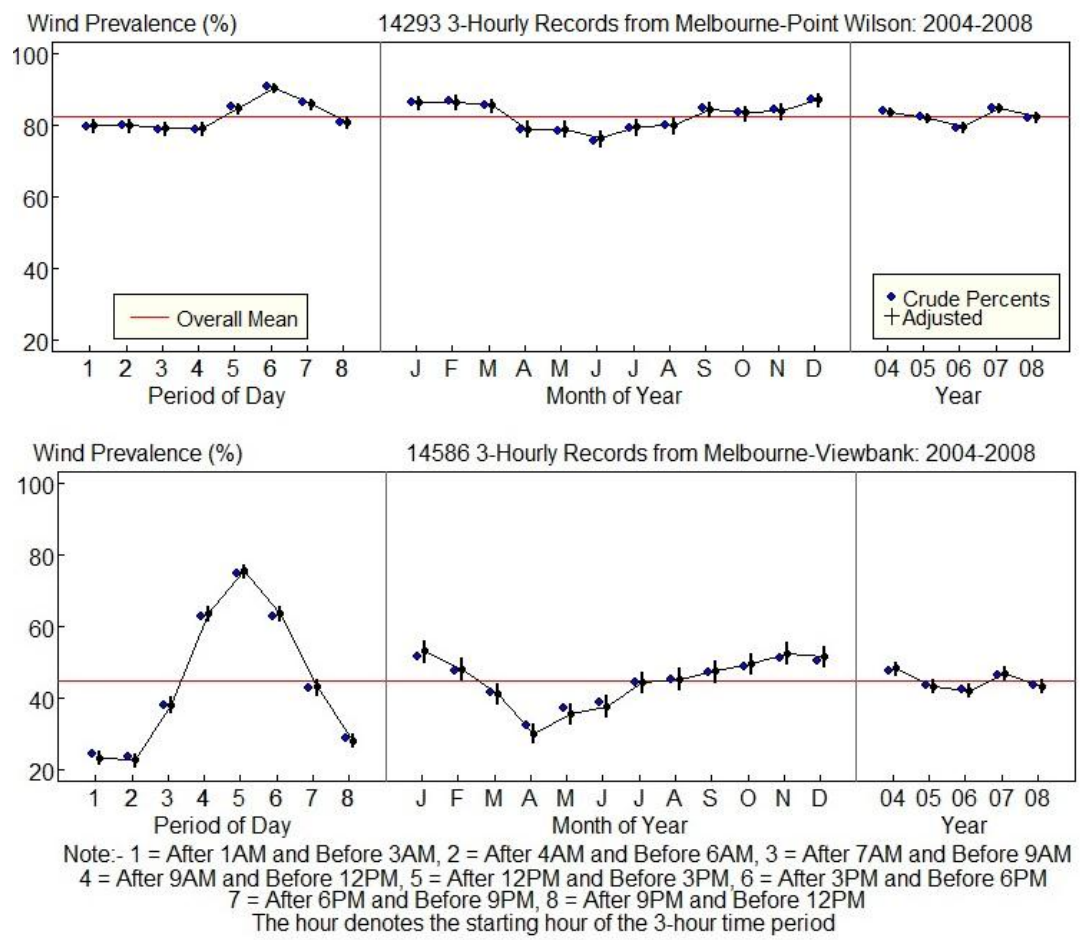

Fig. 3: Patterns of wind prevalence at Point Wilson and Viewbank. 
stations. The prevalence of wind was below the average from $1 \mathrm{AM}$ to $12 \mathrm{PM}$ and peaked during $3 \mathrm{PM}$ to $6 \mathrm{PM}$. Wind prevalence rates were observed to be less than the overall mean from April to August. The prevalence decreased steadily to attain a minimum $(75 \%)$ in June and increased gradually to attain a maximum $(85 \%)$ in December. At the Viewbank station, the overall percentage of wind prevalence (40\%) was lower than the other three stations. However, the pattern for the day, month and year were similar to Avalon and Essendon airports.

Fig. 4 and Fig. 5 reveal the pattern of gusty wind prevalence for the day, month and year and the crude percentage for the selected stations. The horizontal line denotes the overall percentage of wind gust prevalence. The results at all stations were similar to the wind prevalence.

For the stations at Avalon airport, Essendon airport and Viewbank, there were similar patterns of gusty wind prevalence. The highest prevalence occurred from 12 PM to $3 \mathrm{PM}$. The monthly gusty wind prevalence was below the average from March to June and the yearly prevalence were not different from the overall percentage.
At the Point Wilson station, the prevalence of gusty wind was below the average from $1 \mathrm{AM}$ to $12 \mathrm{PM}$ and peaked during $3 \mathrm{PM}$ to $6 \mathrm{PM}$. Wind gust prevalence rates were observed to be less than the overall percentage from April to June and decreased steadily to attain a minimum of 55\% in May and increased gradually to attain a maximum of $70 \%$ in December. The yearly gusty wind prevalence patterns for the selected stations were not significantly different from the overall mean between 2004 and 2005.

Trends and patterns of 3-hourly wind speeds of at least $3 \mathrm{~km} / \mathrm{h}$ for all stations were determined using linear regression models (model 2 ). The model contained the same 3 predictors as the logistic regression models, period of the day, month of the year, and year. The results are displayed using graphical methods as shown in Fig. 7 and Fig. 8.

The quantile-quantile (Q-Q) plot (Fig. 6) illustrates that the residuals from the model are approximately normally distributed. However, there were some deviations from both the lower and upper tails of the model. This deviation may
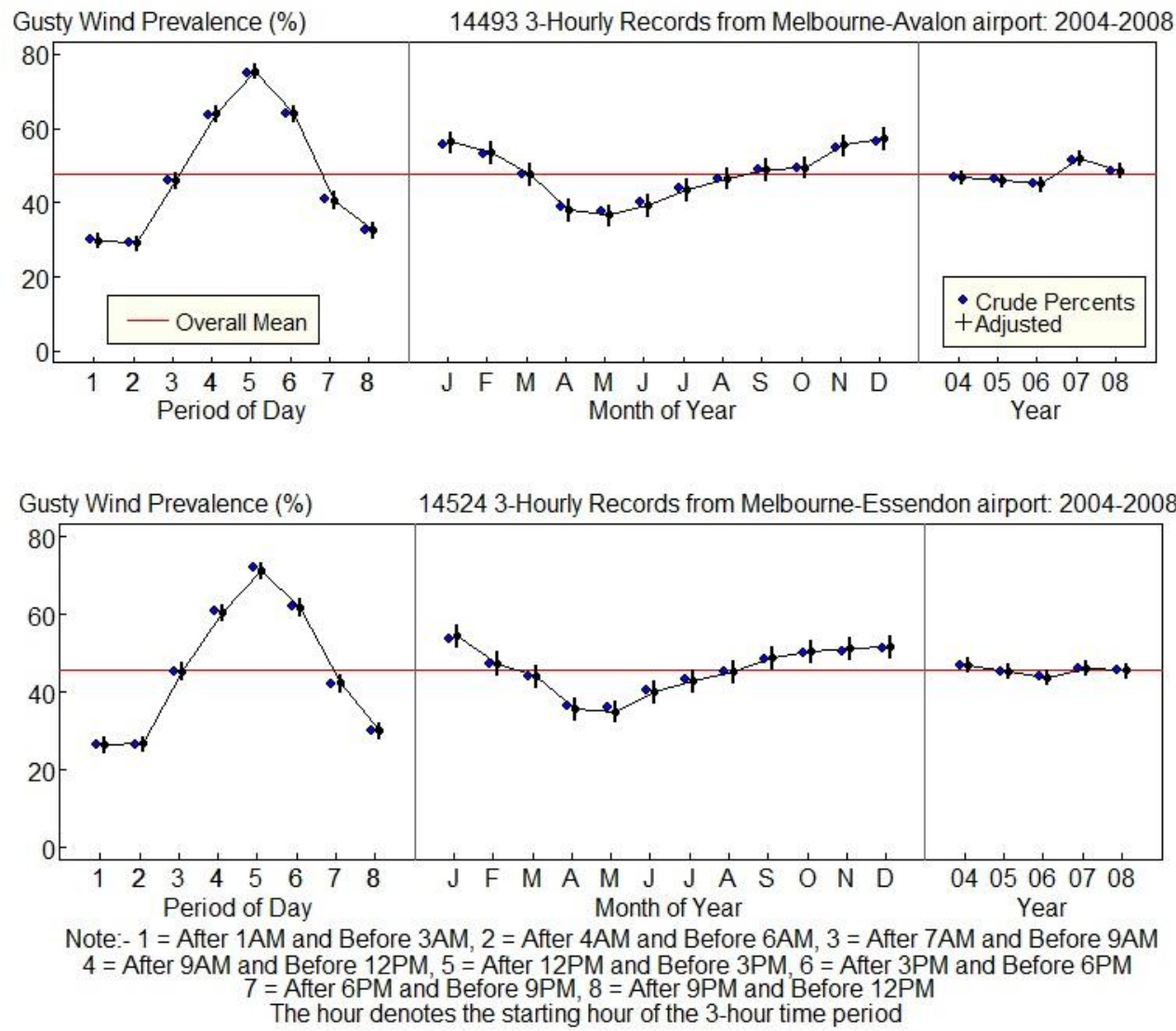

Fig. 4: Patterns of wind gusts at Avalon Airport and Essendon Airport. 


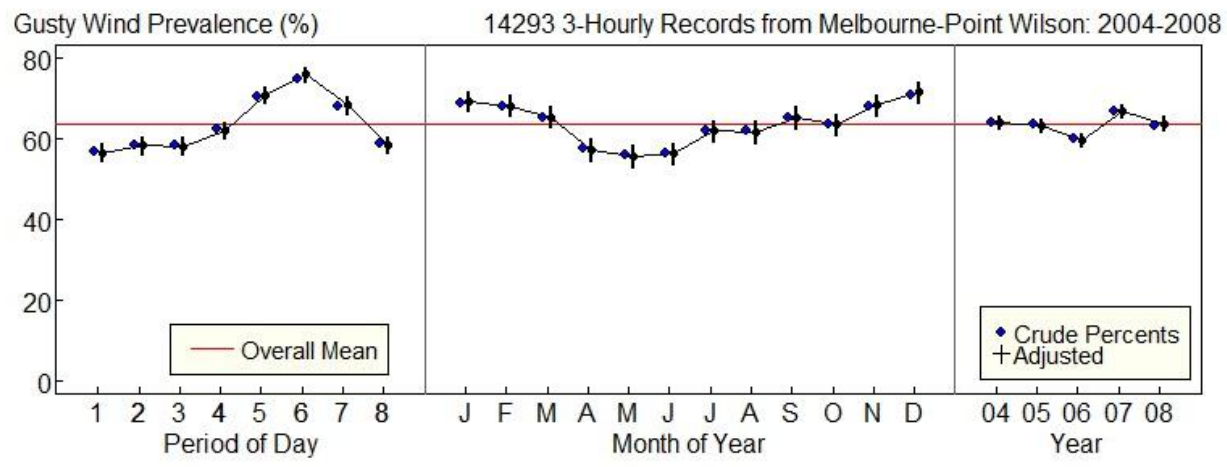

Gusty Wind Prevalence (\%)

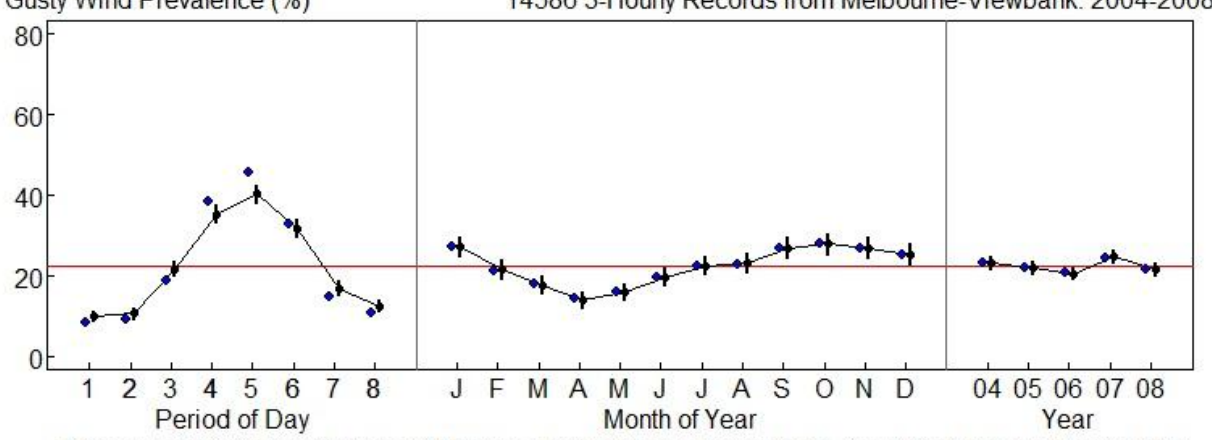

Note: -1 = After $1 \mathrm{AM}$ and Before $3 \mathrm{AM}, 2$ = After $4 \mathrm{AM}$ and Before 6AM, $3=$ After 7AM and Before 9AM

4 = After 9AM and Before 12PM, 5 = After 12PM and Before 3PM, $6=$ After 3PM and Before 6PM

$7=$ After 6PM and Before 9PM, $8=$ After 9PM and Before 12PM

The hour denotes the starting hour of the 3 -hour time period

Fig. 5: Patterns of wind gusts at Point Wilson and Viewbank.
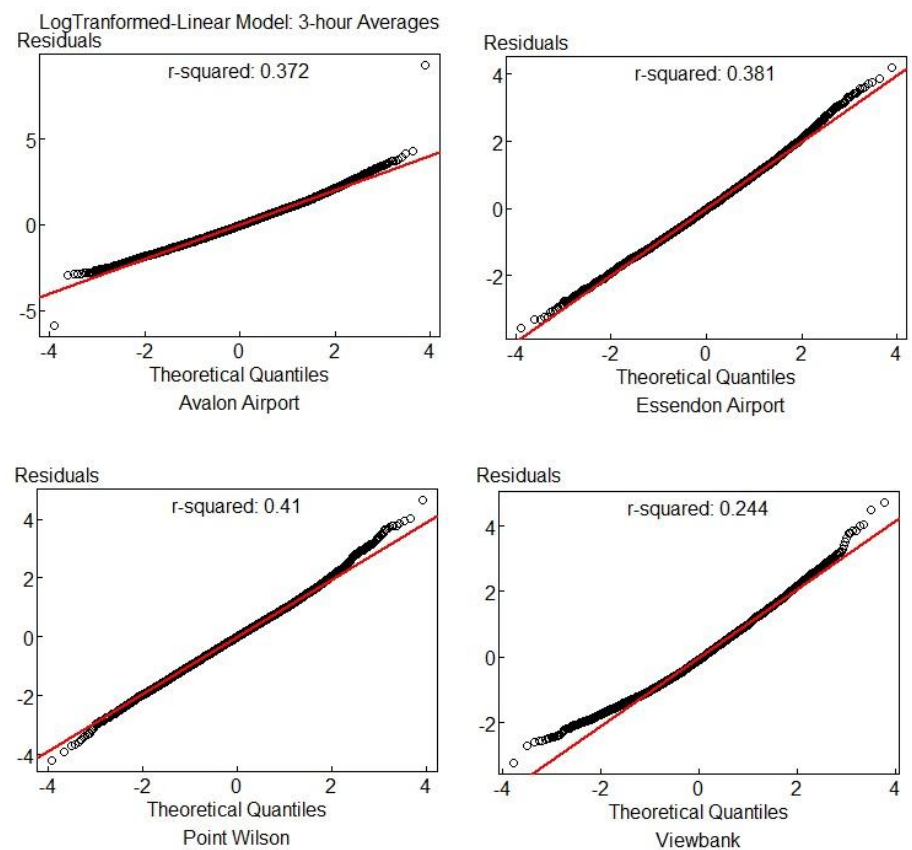

Fig. 6: Q-Q plots for linear models of wind speed at Avalon airport, Essendon airport, Point Wilson, and Viewbank. 
be due to extreme values in the data and some variations that could not be explained by the predictors.

Fig. 7 and Fig. 8 show the wind speed trends for the day, the month of the year, and the year and the crude mean for the four stations. The horizontal red line denotes the overall mean wind speed. The wind speed trends for the day were significantly different from the overall mean.

Four distinct trends were observed for the wind speed at the four stations. At Avalon airport, there was a significant increasing trend from $4 \mathrm{AM}$ to $3 \mathrm{PM}$. A declining trend was apparent from 3 PM to midnight. The wind speed was higher than the overall mean from 7 AM to 6 PM. The wind speed trends were observed to be higher than the overall mean from September to January. The yearly wind speed trend was mostly below the overall mean from 2004 to 2006, but above the overall mean between 2007 and 2008 where the maximum occurred.

At Essendon Airport, the highest wind speed occurred during $9 \mathrm{AM}$ to $12 \mathrm{PM}$. Declining trends were apparent from noon to midnight. The wind speed trends were observed to be higher than the overall mean from September to January.
The wind speed decreased gradually to attain a minimum in May and increased steadily to attain a maximum in September. The yearly wind speed trend was not different from the overall mean.

At Point Wilson, the wind speed was higher than the overall mean from 9 AM to 6 PM. Declining trends were apparent from 3 PM to midnight. The wind speed trends were observed to be higher than the overall mean from July to January. Wind speeds decreased gradually to attain a minimum in May and increased steadily to attain a maximum in December. The yearly wind speed trend was mostly below the overall mean but above the overall mean in 2007 where the maximum occurred.

At Viewbank station there was a significant increasing trend with the highest wind speeds occurring during 9 AM to $3 \mathrm{PM}$. The maximum wind speed occurred in September and the yearly wind speed was highest in 2007.

\section{DISCUSSION}

The 3-hourly wind and wind gust patterns of four stations at Essendon airport, Avalon airport, Point Wilson, and
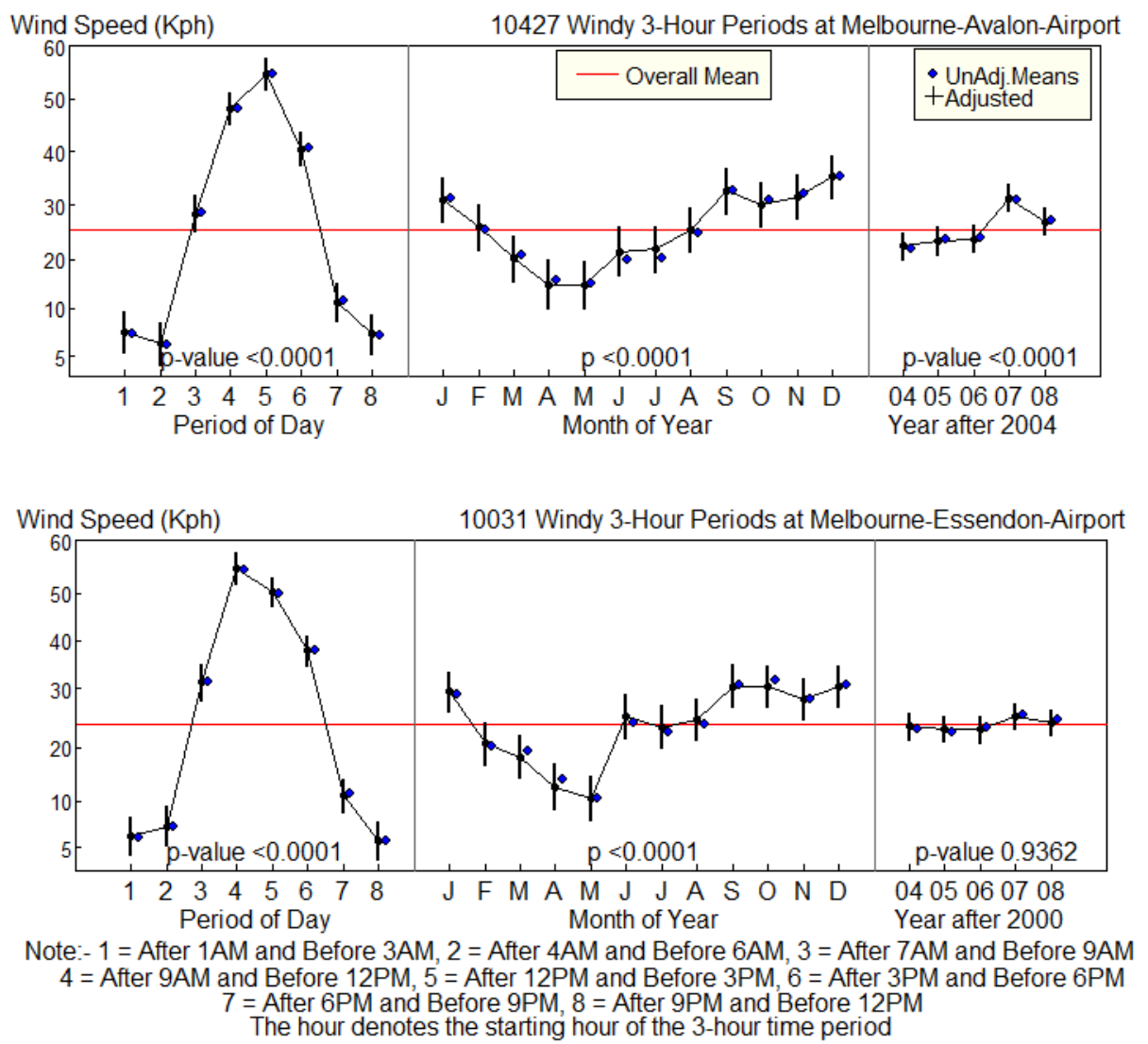

Fig. 7: Wind speed trends at Avalon Airport and Essendon Airport. 

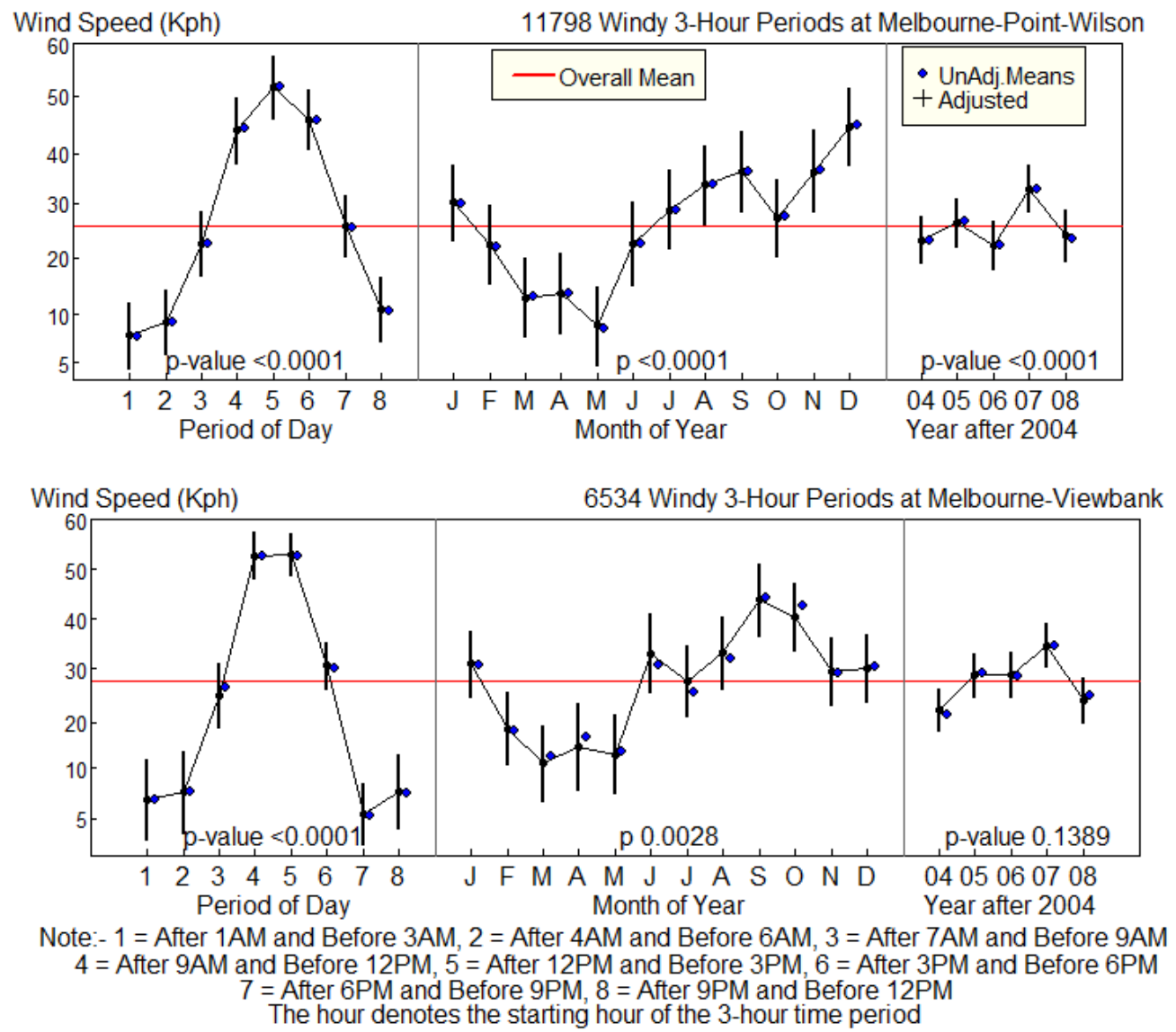

Fig. 8: Wind speed trends at Point Wilson and Viewbank.

Viewbank, Australia during 2004-2008 were similar. The wind prevalence was above the overall average between $9 \mathrm{AM}$ and $6 \mathrm{PM}$ at Essendon airport, Avalon airport, and Viewbank, and from $12 \mathrm{PM}$ to $9 \mathrm{PM}$ at Point Wilson. The wind prevalence was higher than the overall average from September to February and lower than the overall average from March to June at all four stations. This finding confirmed that spring is the windiest time of the year (Carmoday 2016). These observed patterns were due to variability of the surface winds produced by the Asian Monsoon, seasonal variations in the westerly winds in both hemispheres (Hemer et al. 2010), and temporal atmospheric circulation variations (Troccoli et al. 2010) on the north and eastern Australian region.

The linear regression models revealed that the pattern of wind speed among the four stations was not different. The overall mean wind speeds ranged between $25-30 \mathrm{~km} / \mathrm{h}$ with maximum speeds ranging between $50-60 \mathrm{~km} / \mathrm{h}$. The wind speeds were higher than the overall mean during 7 AM to 6 $\mathrm{PM}$ at Avalon and Essendon airports and during 9 AM to 6 $\mathrm{PM}$ at Point Wilson and Viewbank stations.
Wind speeds were higher than the overall mean from September to January and slowly decreased with a minimum wind speed occurring between March and May at all stations. Wind speeds were highest in 2007. Victoria's climate is heavily influenced by coastal force winds, which occur frequently between June and November. During these months, large pressure gradients between high pressures over the continent and deep depressions to the south produce gale-force and occasionally storm-force westerly winds (BOM 2020). In Melbourne, autumn months have lighter winds than other months (BOM 1968).

This study model of 3-hourly wind data using common climatic predictors which described wind trends and patterns. Further investigation can consider other variables that can affect wind patterns and trends such as air pressure, solar radiation, and humidity.

\section{ACKNOWLEDGEMENT}

This work was supported by the Higher Education Research Promotion and Thailand's Education Hub for Southern 
Region of ASEAN Countries Project Office of the Higher Education Commission under grant no. THE/033. We thank Emeritus Prof. Dr. Don McNeil for his supervision. Thanks to the Centre of Excellence in Mathematics, Commission on Higher Education, Thailand.

\section{REFERENCES}

Bett, P.E., Thornton, H.E. and Clark, R.T. 2013. European wind variability over 140 yr. Advances in Science and Research, 10(1): 51-58.

Bureau of Meteorology (BOM) 1968. Climatic Survey: Region 10 - Port Phillip, Victoria, Melbourne.

Bureau of Meteorology (BOM) 2011. Climate, Available at: http://www. bom.gov.au/jsp/ncc/climate_average wind-velocity/index.jsp [January 25, 2017].

Bureau of Meteorology (BOM) 2020. Climate of Victoria, http://www. weather-climate.com/victoria.html [March 31, 2020].

Carmody, B. 2016. Melbourne weather: Why spring has been so windy. https://www.theage.com.au/national/victoria/melbourne-weather-whyspring-has-been-so-windy-20161102-gsg0h5.html [April 30, 2020].

Chen, L., Li, D. and Pryor, S.C. 2013. Wind speed trends over China: quantifying the magnitude and assessing causality. International Journal of Climatology, 33(11): 2579-2590.

Cheng, C.S., Lopes, E., Fu, C. and Huang, Z. 2014. Possible impacts of climate change on wind gusts under downscaled future climate conditions: Updated for Canada. Journal of Climate, 27(3): 1255-1270.

Coppin, P.A., Ayotte, K.A. and Steggel, N. 2003. Wind energy research unit CSIRO land and weather. Wind Energy Research Unit, Australia.

Csavina, J., Field, J., Félix, O., Corral-Avitia, A.Y., Sáez, A.E. and Betterton, E.A. 2014. Effect of wind speed and relative humidity on atmospheric dust concentrations in semi-arid climates. Science of the Total Environment, 487(1): 82-90.

Hemer, M.A. 2010. Historical trends in Southern Ocean storminess: Long] term variability of extreme wave heights at Cape Sorell, Tasmania. Geophysical Research Letters, 37(10): 1-5..

Geer, I.W. 1996. Glossary of Weather and Climate : With Related Oceanic and Hydrologic Terms. Collection Atmosphere.
Glickman, T.S. and Zenk, W. 2000. Glossary of Meteorology, American Meteorological Society, Boston, USA.

Graham, A. and Antony K. 2014. The Romans: An Introduction. Routledge.

Jamaludin, A.R., Yusof, F., Kane, I.L. and Norrulasikin, S.M. 2016. A comparative study between conventional ARMA and Fourier ARMA in modeling and forecasting wind speed data. In Advances in Industrial and Applied Mathematics: Proceedings of 23rd Malaysian National Symposium of Mathematical Sciences (SKSM23) (Vol. 1750, p. 60022).

Klink, K. 1999. Trends in mean monthly maximum and minimum surface wind speeds in the coterminous United States, 1961 to 1990. Climate Research, 13(3): 193-205.

Mitchell, S.J. 2012. Wind as a natural disturbance agent in forests: a synthesis. Forestry, 86(2): 147-157. doi:10.1093/forestry/cps058.

Mohanan, A.H., He, Y., Mcfarlane, N. and Dai, A. 2011. The probability distribution of Land surface wind speeds. Journal of Climate, 24(15): 3892-3909.

Nchaba, T., Mpholo, M. and Lennard, C. 2016. Long-term austral summer wind speed trends over southern Africa: Austral summer wind speed trends over Southern Africa. International Journal of Climatology, 37(6): 2850-2862.

R Development Core Team 2008. A Language and environment for Statistical Computing, R Foundation for Statistical Computing, Vienna, Austria.

Schindler, D., Bauhus, J. and Mayer, H. 2012. Wind effects on trees. European Journal of Forest Research, 131(1): 159-163.

Tongkumchum, P. and McNeil, D. 2009. Confidence intervals using contrasts for regression model. Songklanakarin Journal of Science and Technology, 31(2): 151-156.

Troccoli, A., Muller, K., Coppin, P., Davy, R., Russell, C. and Hirsch, A.L. 2012. Long term wind speed trends over Australia. Journal of Climate, 25(1): 170-183.

Westin, L.K. 2001. Receiver operating characteristic (ROC) analysis: Evaluating discriminance effects among decision support systems. UMINF report, Department of Computer Science, Umea University, Sweden: Available from: http://www.cs.umu.se/research/ reports/2001/018/part1.pdf [December 08 2017]

Wheeler, D. and Clive W. 2004. From calm to storm: the origins of the Beaufort wind scale. The Mariner's Mirror, 90(2): 187-201. 